\title{
Learning Space Evaluations - Timing, Team, Techniques
}

Dr Lisa Germany

Victoria University

Melbourne, Australia 


\begin{abstract}
Many universities are currently investing significant sums of money into refurbishing existing learning spaces and/or building further infrastructure (including Next Generation Learning Spaces (NGLS)) to support learning and teaching in the face-to-face context. While this is usually welcome by staff and students, there is often a concern that designs are not informed by input from appropriate stakeholders.

This chapter brings together information from a range of sources to provide practical ideas and advice on designing robust, whole-of-lifecycle evaluations for learning space projects. By incorporating preand post-occupancy stages, involving a wide array of stakeholders, and looking beyond surveys and focus groups as evaluation techniques, universities can ensure that future designs take into consideration the experiences and context of staff and students at the institution as well as lessonslearned from previous projects.
\end{abstract}

Keywords: learning spaces, evaluation, evaluation cycle, evaluation techniques, design, assessment 


\section{Introduction}

In 2008, researchers from three Australian universities came together to investigate the state of play of learning spaces evaluation (Lee \& Tan, 2011). They felt that while there had been "...much attention to the design of learning spaces ... evaluations of learning spaces have been limited in depth, rigour and theoretical grounding, and were heavily reliant on informal or anecdotal evidence." (p. 3). What they found verified their suspicions, but that is not to say that individual ideas and techniques that could be brought together to form a comprehensive learning spaces evaluation approach did not exist.

This chapter is designed to bring together key information about evaluating learning spaces from multiple sources and provide practical advice on how to design a robust evaluation for a learning space project, including the timing, team and techniques that could be used. We have started to use this framework to ensure designs for new refurbishments, Next Generation Learning Spaces (NGLS) and informal spaces at Victoria University are informed by previous user experience and align to University strategic priorities.

\section{Timing}

Typically, if a learning space is evaluated at all, the evaluation occurs once teachers and students have started using the space. This is known as a post-occupancy evaluation and is often used to elicit feedback on what staff and students like and don't like about a particular space. While this is useful information to feed-forward into the next learning space project, it occurs far too late to ensure the space under investigation will meet the expectations of the users and the institution.

For this reason, several authors have argued that pre-occupancy evaluations (evaluations undertaken before the space is ready for use) are also critical in any learning space project. Lee and Tan (2011) proposed a model for the development of learning spaces in which evaluation at the key stages of design, construction and occupation elicits concerns and ideas from staff and students, and foregrounds them to be addressed or incorporated before the next stage is undertaken. The Pedagogy-SpaceTechnology (PST) Design and Evaluation Framework (Radcliff, 2008) also takes this approach but recommends that evaluations begin even earlier, at the concept stage, aligning with the advice of Lippincott (2007) and the practice of Lee (2008). The following sections draw upon the ideas of these and other authors to outline the types of evaluation that should be incorporated into the various stages of a learning space project.

\section{Concept stage (Pre-occupancy)}

Evaluation at the concept stage of a learning spaces project should be undertaken at several levels to arrive at a complete and common understanding of the intended outcomes and possible impacts across all stakeholder groups. It can be argued that without understanding the institutional motivations for the project, the post-occupancy evaluation will be unable to measure the degree to which the original goals of the project have been met (Powell, 2008).

At the highest level, evaluation at the concept stage is about clarifying the purpose of the project and the desired outcomes for the institution (Lippincott, 2007). This includes a robust discussion of plans for the future of learning and teaching at the institution, and what additional initiatives (e.g. curriculum redesign, professional development) may be required to support staff and students in transitioning their practice to align with this ideal (Radcliff, 2008).

These discussions should be informed by an evaluation at the user level that elicits information from staff and students about what they perceive as working well and what they perceive as lacking in the institution's current suite of learning spaces. They should also take into account "lessons learned" from 
Learning Space Evaluations - Timing, Team, Techniques previous learning spaces initiatives, particularly around stakeholder engagement and issues with implementation (Radcliff, 2008).

\section{Design stage (Pre-occupancy)}

With the high level outcomes for the learning spaces project determined during the concept stage, the design stage evaluation should be focused around gathering and analysing:

- student and staff feedback from post-occupancy evaluations of previous learning spaces initiatives;

- $\quad$ student and staff design ideas for the proposed space (e.g. Gibbons \& Foster, 2007);

- feedback from IT/AV and facilities departments around maintenance and technical support, based on previous learning spaces initiatives;

- feedback from academic support around usability and training, based on previous learning spaces initiatives, and;

- ideas and best practice from projects that achieved similar outcomes at other institutions (Lee \& Tan, 2011; Radcliff, 2008).

This information should then be synthesised and used to further inform initial design concepts.

Although all stakeholder groups should be represented in the design team itself, the broader user community should also have the chance to provide feedback on iterations of design concepts. Lee (2008) created a reference group consisting of students, academics, management, and services departments for this purpose, and at Victoria University we are holding open forums where all users at the relevant campus are invited to participate and provide feedback. We have adopted several designchanging ideas articulated through these forums, and intend that this opportunity for staff and students to evaluate design concepts will encourage personal engagement with the spaces (perhaps as a champion or at least an advocate) once the space is complete.

\section{Construction stage (Pre-occupancy)}

The main type of evaluation that takes place during construction is carried out internally within the project team and is primarily related to project management - is the project on time, on budget and within scope with little risk. It is during this stage that those departments that work closely with contractors should evaluate the working relationship, an assessment that may potentially influence future engagement with the company.

However, it is also the time to ensure that stakeholders are kept up to date with progress (Lee \& Tan, 2011), and while this is not strictly an evaluation, it can again influence engagement and evaluation feedback down the track. Examples of communications may include:

- updates on construction progress and any special considerations that have been taken into account in the scheduling. For example, letting everyone know when demolition will start and the fact that the project attempted to schedule this noisy work for during the semester break and outside of core teaching hours;

- promotion of the types of spaces that are being constructed, including the rationale behind the design, and computer generated imagery of what the spaces will look like once completed;

- information about the types of technology that will be available in the spaces, and;

- practical advice about how the spaces might be used pedagogically for a variety of disciplines.

By maintaining regular communications about the spaces under construction, it is possible to build excitement and encourage staff to start thinking about how they might utilise these new opportunities. It also ensures that staff and students are aware that although they may be inconvenienced during the construction phase, the project has tried to minimise these disruptions. 
The occupation stage is a critical time for evaluation, providing an opportunity to explore whether the space has achieved its intended purpose as specified during the concept stage. To date, the majority of learning space evaluations have focused on gathering information once staff and students have occupied the space and, in summary, were designed to elicit information that demonstrates value or effectiveness, measures satisfaction, reveals unintended use cases and identifies needed changes (Lippincott, 2007).

Often, however, these evaluations are only carried out once, relatively soon after the space has opened. Unfortunately, it is unlikely that a single evaluation will provide sufficient information to assess the success of the space and inform future learning spaces projects, as some of the desired effects of a project (for example, a change in teaching practice or assessment practice) may take some time to manifest. To this end, a more extensive timeline for post-occupancy evaluation might include:

1) 1 month after occupancy - to gather data on users' first impressions and perceptions of how the spaces will work (Dowling \& Lee, in progress)

2) 6 months to 1 year after occupancy - to measure the differences between first impressions of a space and actual experiences over time (Dowling \& Lee, in progress).

3) longitudinal - to determine whether the space has a long-term impact on teaching practice and student learning and whether the design was future-proof (including from a maintenance perspective). In particular, it would be useful to explore whether teachers have incorporated new assessment techniques that make full use of opportunities that may be provided in the NGLS (Crisp, 2014).

At each of these timings, there are a large number of elements to potentially be evaluated, all of which feed into how staff and students use and experience the space. The Technology, Architecture and Furniture model (Education Queensland, 2013, "About TAF") suggests a division of these elements into four main categories: Environmental, Functional, Emotional and Pedagogical (Table 1), in which each of the main groups of stakeholders should have various levels of interest. For example, one might expect teachers and students to have a keen interest in all four categories as they all impact the user experience in the space. On the other hand, although IT/AV staff may primarily be interested in the Functional category (to determine how well the technology has worked and what maintenance issues have arisen), they could also be looking at elements in the Environmental category (to determine how the acoustics, lighting and temperature have affected performance of AV equipment) and the Pedagogical category (for feedback on how cables and wiring are potentially impacting pedagogy in the space) for a full understanding of what has worked and what hasn't with respect to the IT/AV fit-out of the space.

Table 1: One possible categorisation of the different elements of a learning space that should be evaluated

\begin{tabular}{|l|l|l|l|}
\hline Environmental & Functional & Emotional & Pedagogical \\
\hline Indoor air quality & Furniture (chairs, tables) & Colour & Flexibility \\
\hline $\begin{array}{l}\text { Acoustics (internal, } \\
\text { external distractions) }\end{array}$ & $\begin{array}{l}\text { Fixtures (whiteboards, } \\
\text { pinboards, power) }\end{array}$ & Vistas & Configuration \\
\hline $\begin{array}{l}\text { Lighting (daylight, } \\
\text { artificial light) }\end{array}$ & $\begin{array}{l}\text { Technology (WiFi, } \\
\text { projection options, } \\
\text { computing options) }\end{array}$ & Security & Student outcomes \\
\hline $\begin{array}{l}\text { Temperature (heating, } \\
\text { cooling) }\end{array}$ & $\begin{array}{l}\text { Adequate space for } \\
\text { number of students }\end{array}$ & Ownership & Teacher outcomes \\
\hline & Accessibility & & \\
\hline & Floor coverings & & \\
\hline & Utilisation & & \\
\hline
\end{tabular}

While few would disagree that "Learning, rather than heating systems, lighting controls, or computer projectors, should be at the center of learning space design." (Oblinger, 2004, p. 1), it does assume that the Environmental and Functional elements of a learning space are the best they can be to support learning. However, we know from experience that this is often not the case, and several papers have 
Learning Space Evaluations - Timing, Team, Techniques linked poor environmental elements with reduced student engagement (Hunley \& Schaller, 2006) and impacted student achievement (Higgins, Hall, Wall, Woolner, \& McCaughey, 2005).

In a recent series of focus groups conducted at Victoria University, the primary concerns of teaching staff were around these environmental elements. It quickly became clear that teaching staff did not have the headspace to discuss the functional or pedagogical elements of the spaces, as questioning along these lines was almost immediately turned around to environmental issues once more. In a way, this aligns with the fundamental premise of Maslow's Hierarchy of Needs (Maslow, 1943), the idea that our most basic needs must be satisfied before we are ready to consider more advanced needs. In the learning space context, if there are issues with the heating, cooling or air quality, we are not going to be thinking about technologies and pedagogies to support learning.

This demonstrates that while it might be tempting to leap right to the heart of the matter and evaluate the impact of space on the high-level goals as defined in the concept stage, investigating the environmental and functional basics to understand how they feature in the feedback from staff and students is an important part of post-occupancy evaluation. It is critical for understanding what has worked, what hasn't and what should be altered for next time.

That's not to say that the high-level goals should be ignored. In their investigation into the state of play of evaluating learning spaces in the University sector, Lee and Tan (2011) did find a tendency for evaluations to gather feedback predominantly around the functional aspects of the design and staff and student satisfaction with the space. This is possibly because robustly examining how a space impacts student achievement or teaching practice is very difficult, and convincing techniques and evidence to support these notions has only emerged recently.

In particular, the learning spaces research team at the University of Minnesota has had the unusual opportunity to apply a quasi-experimental approach to investigating their new Active Learning Classrooms (ALC). They have partnered with instructors who teach identical sections of their courses in two very different learning environments - a traditional classroom with student tables facing the front of the room, and a technology-enhanced active learning space equipped with collaborative tables and multiple LCD screens. Brooks (2011) showed that students taught in the ALC outperformed their peers who were taking the same course in the traditional classroom, and Brooks (2012) showed a causal relationship between the physical space and the behaviour of teachers and students.

These are two of the first studies to robustly explore the pedagogical elements of learning spaces and strongly suggest the worth of one design over the other. It demonstrates that this ultimate aim for our evaluations, although difficult to achieve, is possible.

\section{Team}

Several authors have provided recommendations for who should be involved in the design phase of learning spaces projects. Oblinger (2004) suggested that administration, teaching staff, students (undergraduate, graduate), facilities, planning, information technology, library and teaching and learning support should all be at the table during this phase of a project. The Next Generation Learning Spaces Project at University of Queensland (Radcliffe, 2008) added design and technology professionals from the University and nationally to the list, while Lee (2008) kept the design group small but formed a reference group (students, teachers, management and services departments) and a management group to contribute to the Project Hub at Swinburne University of Technology.

These recommendations align with Jamieson's (2007) observation that different areas (Facilities, timetabling, IT/AV, teachers, academic developers, architects, students) have potentially conflicting ways of 'seeing' classrooms within universities, dependent on their involvement in and responsibility for them. As a slightly simplistic example, a facilities department might see spaces as projects and assets that need to be managed, space management and timetabling may see a complex jigsaw puzzle that needs to be arranged in such a way that utilisation is maximised, AV/IT see spaces in terms of what technology could be installed, teachers see spaces for engaging with students, and students, spaces to engage with their teachers and learn. A concrete example comes from Dane (2008) who wrote of a Space Allocation 
Learning Space Evaluations - Timing, Team, Techniques Manager who raised the issue that the 'utilisation rates' for a new generation learning space were below expectations. This was in contrast to teachers involved in the pilot who were unanimous in their support for the space and the collaborative learning it encouraged.

While the literature offers up some advice about who should be involved in the design of learning spaces, far less has been written around who should be involved in the development of evaluation protocols and instruments. In particular, one might conclude from the discussion of timing in the previous section, that different stakeholders might take the lead on the evaluation in different stages of the project. For example, executives within the organisation with responsibility for learning and teaching should perhaps drive evaluation in the concept phase, the design team (including architects) should drive evaluation in the design phase, and facilities managers should drive evaluation during the build phase of a project.

For post-occupancy evaluations, it makes sense that at least some members of the design team (those familiar with social research methods) should be involved in the development of evaluation instruments to ensure that the evaluation aligns with principles and proposed outcomes for the space. However, this could also be used as an opportunity to invite other stakeholders with an interest in learning spaces and the scholarship of learning and teaching to bring in other perspectives.

Taking it one step further, inviting students into the evaluation team provides insight into what normally happens day-to-day in the type of space under evaluation, and may reveal alternate lines of questioning that would otherwise not have been considered. This has been used to great effect by the learning spaces evaluation team at the University of Minnesota who have established a Learning Environments Research Partnership Model that includes undergraduate students, faculty members teaching in the space and a research expert (Walker, Brooks, \& Baepler 2011). In particular, the undergraduate researchers "....worked with the other team members to establish the project's research design, create the research instruments, and collect and analyse data." They also "...underwent training on the protection of human subjects and research methodology." (http://www.educause.edu/ero/article/pedagogy-and-space-empirical-research-new-learningenvironments), setting them up for the future if they decide to pursue social research avenues.

\section{Techniques}

Social science literature advocates for studies that utilise several different evaluation methods so that key themes and issues can be triangulated across multiple techniques. If the same findings can be concluded from more than one set of data, we can be more confident about the validity of our results.

There are many different traditional and innovative evaluation methods that could be used at any stage of the concept-design-construction-occupation cycle for a learning space. The following examples showcase several ideas that have come specifically from the evaluation of learning spaces. Where possible, references have been provided for more detailed information and examples.

\section{Surveys}

Surveys are one of the most commonly used tools for learning space evaluations as they are easy to administer, can potentially reach a large user base, and are not time-intensive for researchers. While they can be effective in ascertaining the level of satisfaction of users with the space and the various elements contained therein, the data they elicit tends to be broad rather than deep and they are rarely able to reveal why the users feel the way they do. To this end, they offer little guidance for the design of future building projects (Powell, 2008) and are often followed up with focus groups to probe more deeply around the ideas uncovered by the survey.

\section{Individual Reflective Techniques}


Learning Space Evaluations - Timing, Team, Techniques In these techniques, students are essentially recruited as co-researchers and asked to record their own actions or reflect on a question in order contribute to the data gathered for evaluation. These techniques often reveal detail in the thoughts and the day-to-day life of a student that conventional interviews alone could not achieve.

\section{Design Charrettes}

A charrette is an intensive process through which draft solutions to a design problem are created. Gibbons and Foster (2007) used this technique in their Undergraduate Research Project, providing the following scenario to participating students: "Imagine that the library has a big, new, empty space ... and they ask YOU to design it. You can put up walls or not have walls. You can buy furniture, hire staff, have the amenities and comforts that you want ... It is exactly the way you wanted it to be and you love it and want to go there a lot. Show us what it looks like." (p. 22). Nineteen students took part, and although individual designs had some unique "quirky" elements, five common elements also emerged from this process giving them a good baseline from which to work.

When it came time to look at the fittings and furnishings of the space, Gibbons and Foster (2007) ran a second series of design charrettes with students. In this iteration, they gave students "...a plan of the space and a wide selection of furniture cutouts made to scale, along with markers, sticky notes, scissors, and glue. ... [and asked them] to design and furnish the space to meet their needs." (p. 26). Again, there were remarkable similarities between the twenty-one finished designs, and disturbingly, these designs did not in any way reflect the designs created by the library renovation team on how they thought students would like the space arranged.

\section{Photo Surveys}

In this technique, participants are given a list of things to photograph over a period of time. Once they have obtained their images, they are interviewed to elicit further information about the images taken and how they relate to the items on the list.

Briden (2007) used this technique to see from the student perspective, specific items of interest to their study of undergraduate student life at the University of Rochester. Having students contribute imagery on, for example, their favourite place to study, and then following up with individual interviews to reveal why, "... provided answers to specific questions we were asking, ... gave us hints that were confirmed through other investigations, and other [findings that] were completely unexpected." (p. 45).

A similar approach was used by Nixon, Tompkins \& Lackie (2008), in which students were asked to take no less than 5 images corresponding to a how they went about completing a particular assignment, and 5 images on how they use and feel about the campus in general. Prompts for each were provided to assist the students in formulating the type of photos that might be relevant. The photographs were used in follow-up interviews where students were asked to elaborate upon their decisions to take the photos, and the images themselves.

Keppell and Riddle (2012) also incorporated this technique into their exploration of technology use. Students were texted at irregular intervals over a 24 hour period and encouraged to take photographs of where they were, what they were doing, who they were with and how they were feeling. These photographs of their "day" were then discussed in a focus group scenario.

\section{Visual mapping}

The essence of the visual mapping technique is that participants are provided with a map of the area under evaluation and asked to draw in where they go during a typical visit. For example, Jordan and Ziebell (2008) asked students to mark the sequence of their activities on a floor plan and include comments about what activities they did and how long they spent on each activity.

Clark (2007) "...gave students a map of the campus and key surrounding areas and asked them to mark their movements [over the course of one day] on this map, indicating when they arrived at each place and when they left it." (p. 48). Students were interviewed about their day when they returned their map. In fact, follow up interviews with participants are common in this technique, in order to better understand the information in the map. The technique has also been modified for use in focus groups for this reason (see below). 
Learning Space Evaluations - Timing, Team, Techniques Nixon et al., (2008) modified the technique of Clarke (2007) to track movement over a longer period of time and to be able to clearly indicate multiple visits to a single location. It was also modified to be able to elicit information about specific locations within the individual buildings on campus. This mapping exercise (along with the photo surveys described above) provided the basis for the follow-up interview with researchers about how students utilise the campus.

\section{Reflective Diaries}

In this approach, participants describe, or better still, reflect on their activities over a period of time in a diary. This appeared to work well for Anders, Calder, Elder, \& Logan (2008) who had focus group participants document their use of different spaces in order to further validate focus group information, however, Gallagher, Pearce, \& McCormack (2008) point out some limitations to the method. They found that despite providing students with careful training in the use of the diary, the entries tended to be descriptive rather than true reflections. While this may be sufficient to gauge student satisfaction with learning spaces, it falls short of revealing what impact the space has had on student learning, the purpose of their evaluation.

\section{Other techniques}

Although the study of Keppell and Riddle (2012) was specifically mentioned in relation to photo surveys, they actually mixed several of the above techniques and offered students the opportunity to use a camera, a diary or a voice recorder to record their moment in time. By offering students a wide variety of tools to capture their reflections, they "...encouraged the participants to provide as rich and detailed an account as possible of their experiences." (p. 13).

Gallagher et al., (2008) drew upon the unique opportunity presented by the Victoria University Rovers students who occupy a support role within the Learning Commons spaces under evaluation at the University. In particular, they tapped into the end-of-shift reports submitted by each Rover, transcripts of Rover debriefing sessions and reflections on the Rover blog to augment data collected through student reflective diaries and surveys. However, they acknowledge that "...more effective methods need to be developed to triangulate the perceptions of the Rovers themselves with those of student users of the [space]." (p. 104).

\section{Facilitated Group Discussions}

Facilitated group discussions (usually in the form of focus groups) are another mainstay of learning spaces evaluations and are typically used to follow up on ideas that have emerged through a survey. The most common format for these discussions is a semi-structured interview that prompts the participants for further information that may help to interpret the survey results.

While focus groups provide a quick method for gaining multiple perspectives, they do have limitations. In particular, and in the context of learning spaces evaluations, Lee and Tan (2013) identified that the interview-based formats "...yielded little useful data for a deeper understanding of design requirements [and had] ... a tendency for 'group think' or dominant members to overwhelm the data." (https://libjournal.uncg.edu/index.php/jls/article/view/503). Several techniques have emerged to try and overcome these barriers.

\footnotetext{
"Movers and Shapers" Focus group

The "Movers and Shapers" focus group method used in the Learning Landscape Project at Cambridge University (Howell, 2008) endeavoured to break down the stranglehold of dominant participants and "group-think" common in traditional facilitated group discussions. In this approach, participants are divided into groups for a series of 15 minute "mini-discussions" around a table with a facilitator. At the end of the 15 minute time interval, participants at each table randomly select a card that identifies them as either a "mover" or a "shaper". The "movers" change tables and enter their new mini-discussion to challenge what has gone before. The "shapers" remain at their table and attempt to convince the "movers" of what was previously discussed. This is repeated until the end of the session, which lasts at least an hour. These focus groups produced a wealth of qualitative data and were found to be stimulating and engaging for participants.
} 


\section{Diamond Ranking within a focus group}

Learning Space Evaluations - Timing, Team, Techniques

Participants are divided into groups and given nine images to consider. Each group is required to rank the images in terms of preference and form them into a diamond shape with the most preferred image at the top of the diamond and the least preferred image at the bottom (Woolner et al. 2010). Participants are then encouraged to annotate the diamond to further explain their rankings.

Lee and Tan (2013) applied this technique to the evaluation of an informal learning space at Swinburne University of Technology, giving students nine images of different areas within the learning environment to rank according to preference. Rather than using annotations, they had each group of students discuss and provide the rationale for their preferences, explaining how they decided upon their arrangement. Further discussion was used to explore consensus or disagreement within the groups.

Both sets of researchers found that this technique was very good for invoking self-generated discussion within the group, as it required participants "make the case" for their preferences in order to achieve group consensus on the ranking.

\section{Visual Mapping within a focus group}

Woolner et al. (2010) also utilised two versions of the visual mapping technique described in the Reflective Techniques section above. In one version, they had students and school staff indicate on their maps the places they liked and places they didn't like with different coloured stickers. In the other, they had participants indicate "places that work" and "places that don't work" on their maps. Researchers then initiated discussions within the focus group context to elicit explanations, opinions and ideas from the participants.

Lee and Tan (2013) modified this technique further by asking participants to draw their typical route on a transparency overlaid on a map of the space under evaluation. Maps from all participants were then overlaid on top of each other and the resulting discussion explored the similarities and differences for individual routes.

\section{Evaluation by Design within a focus group}

Jordan and Ziebell (2008) extended the design charrette technique discussed previously to the focus group scenario. They undertook design workshops with groups of students, asking them to sketch their ideal spaces that would best support three different types of learning activity: group work, individual assignment work, and preparing for exams.

Lee and Tan (2013) expanded upon this idea giving their groups of participants a selection of abstract objects (pins, string, beads, ice cream sticks, etc.) to design their ultimate space, rather than having them sketch it. The idea is that these "play" objects would provide "...sufficient and flexible items that would facilitate creative solutions, promote positive play and not confuse or overwhelm participants." (https://libjournal.uncg.edu/index.php/jls/article/view/503). To guide the process, they specifically asked participants to first think about the space itself and consider what type of equipment they would have and where they would place it. They were then asked to specifically consider the use of technology in the space. A whole-of-group discussion within the focus group setting then elicited further information on choices made and drew out rationales for the similarities and differences in the designs.

Figure 1 shows an example output from this type of activity run during the evaluation of a NGLS at Victoria University. The NGLS was a very flexible space with large areas of writable surface, flip-top tables on castors, LCD screens for students to plug into and a variety of hard and soft furniture. Each group of participants ( 3 in each group) was given a large sheet of paper that approximated the shape of the space under evaluation, and play objects to represent different elements in their redesign of the space. Boxes 1-5 in Figure 1 indicate elements that already exist in the space and the box 6 shows a completely new addition proposed by the group. In looking at the physical design, and in the discussion that ensued, the following information was revealed:

Box 1: In this area there is a writable surface and an LCD screen that a student group can plug their laptop into for better visibility of the screen. The group has made a note "magic button that you press and this screen always works", indicating that there were issues with the technology during the semester. Staff verified in the discussion of their design that there had been several issues in students being able to connect their laptops successfully to the screens around the room. 
Box 2: This existing area has a curtain that can be pulled around into a circle to isolate a group of students in a private space. Even despite the issue during the semester of the curtain falling off the rail (hidden behind the upright paper is a note to "please fix the curtain"), the fact that it appears in the redesign suggests it was seen as a valuable design element in the space and a couple of members of this group revealed in their commentary that they used this to isolate a specific activity that students would rotate through.

Box 3: These pipe-cleaner rectangles represent the easily moveable flip-top tables available in the space. Staff commented on how easy they were to operate and move around the room to enable different styles of group work, and appreciated the opportunity to fold them all up on occasion and push them completely out of the way.

Box 4: The space has a number of upholstered low stools for students to sit on. This group suggested that the space should have additional workspaces at different heights to encourage different types of interaction, and have added round tables at standing height (similar to tables often found at cocktail receptions) and bar stools in their design.

Box 5: This side of the room is a wall of windows under which there is bench seating. The bench seats were clearly a favourite in the room as indicated by the love-hearts.

Box 6: This area is "hidden" or sectioned off when the main projection screen is activated and extends from the ceiling. The group felt that it was a bit of a "dead" space that could be better utilised as a structured soft area with further bench seating, low tables and beanbags. They felt that because it was isolated behind the projection screen, this could be a "quiet area" to escape the hustle and bustle of the rest of the activity going on in the space. Informal observations of how students use the space outside of class time revealed that this area was usually where students could be found lying on beanbags working quietly - anecdotally validating that it is seen as a bit more of a quiet, secluded area. 


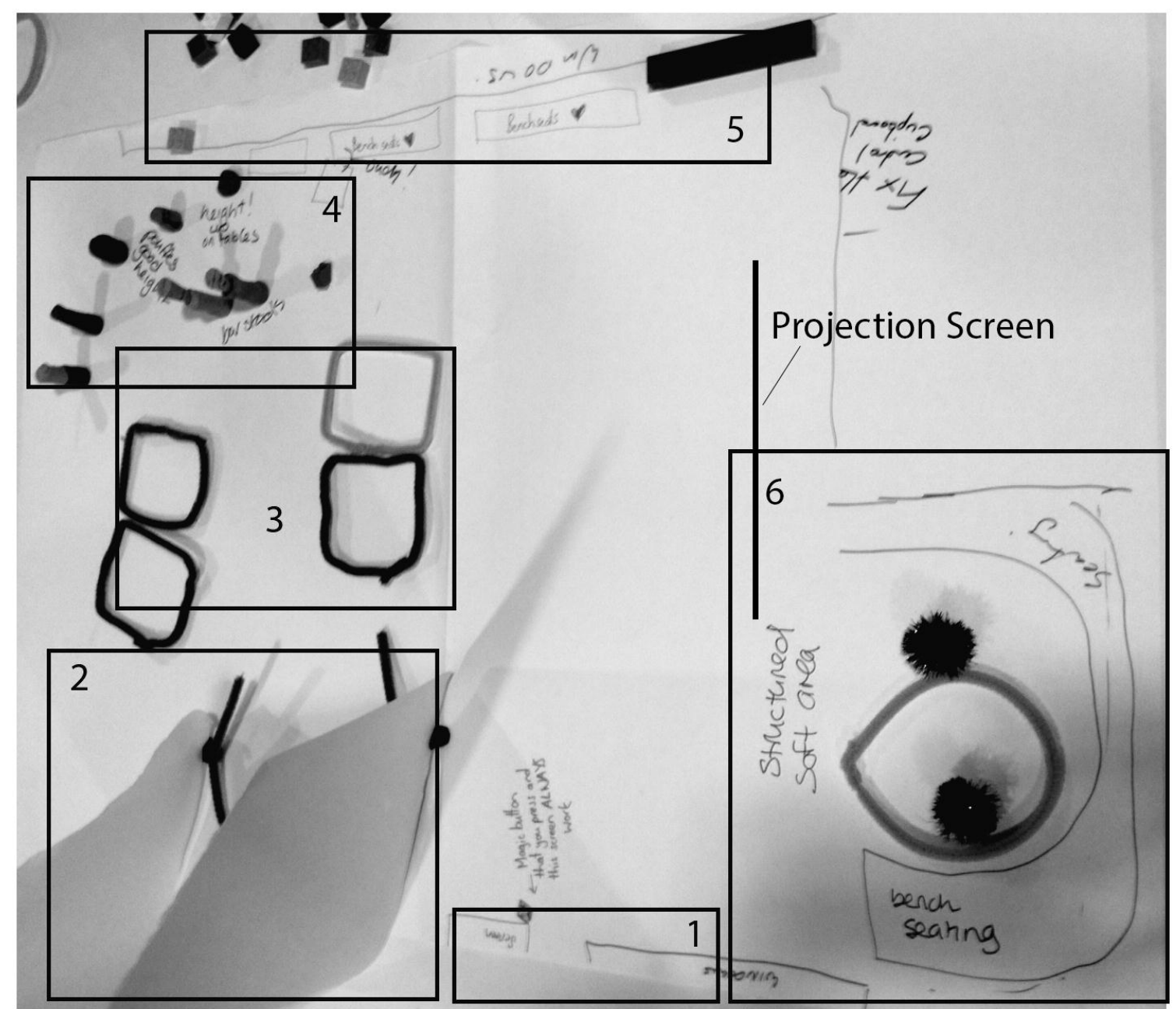

Figure 1. Example output from an "evaluation by design" activity within a focus group.

\section{Observations}

Passive observations are not as prevalent in the literature around learning spaces evaluation, possibly because they are best performed by trained observers and can require a significant investment of time. However, they do offer particular advantages in that they provide rich information of how a space is actually used and an important validation of self-reported behaviours of students and teachers (Hook and Rosenshine, 1979). The ways in which observations have been used in learning spaces research ranges from informal, ad-hoc observations through to carefully tested, rigorous observations, and everything in between.

In the evaluation of the Science Learning Centre (Matthews, Andrews, \& Adams, 2011), researchers recorded general observations about the space for 15 minutes and then observed a specific group of students or an individual for another 10 minutes. Information such as activity, location, interactions, mood, reactions to the environment and "interesting events" were collected before the individual or group was approached to participate in a 10-15 minute informal interview. Comments made by the students in these informal interviews were later verified with their observed behaviour. 
Perhaps the most rigorous use of observation has come from the team at the University of Minnesota who developed and made extensive use of an explicit observation protocol in the evaluation of their new Active Learning Classrooms (Whiteside, Brooks, \& Walker, 2010; Walker, et al., 2011; Brooks, 2012). This protocol has been tested for reliability and validity and requires the observer to document specific activities (identified in the observation form) occurring in the classroom at intervals of 5 minutes. These observations were a critical component in the quasi-experimental approach that allowed the researchers to demonstrate the causal relationship between the physical space and the behaviour of teachers and students (Brooks, 2012).

The above examples require a researcher to be present in the space in order to carry out the observations. However, several contributors to Radcliffe, Wilson, Powell, \& Tibbetts, (2008) have suggested making use of remote video recording to do the same. Mitchell, Winslett, \& Howell (2008) in particular suggested making use of "...time-lapse recording of the way in which the space is configured and reconfigured by students ... [in order to] provide an understanding of how the use of space changes across the academic semester." (p. 92).

These same researchers also reported a more radical take on traditional observation methods where, rather than observing students directly, they undertook an informal analysis of the level of activity undertaken in group collaboration sessions by investigating the student content left on the whiteboards at the end of each day. This revealed that mobile collaboration opportunities were used twice as much as the same opportunity if it was fixed to a wall.

Another alternative method to traditional observation has been utilised by Hunley and Schaller (2006) who made use of photographic techniques to enable their observations. Specifically, in the initial evaluation, photographers followed a designated path through the buildings under evaluation to take photographs from designated locations each hour, at roughly a quarter past the hour, for a week. The intent is now to build up a longitudinal study of how the spaces are used over a two year period.

\section{Institutional data}

A final way to evaluate learning spaces is through the use of "institutional data". This is a bit of a catchall that includes data that is automatically logged by some means. In the case studies presented in Radcliffe et al. (2008), several examples of institutional data are mentioned including computer login data, wireless usage data, room booking data, door counts and helpdesk enquiries. Other possibilities include information from remote management tools (e.g. from room AV control systems), Radio Frequency Identification (RFID) tracking and incidents reported through facilities and IT service desks. Opportunities for gathering institutional data to assist in the evaluation of learning spaces are limited only by what data is automatically collected by your institution, their policy and your imagination.

\section{Take homes}

This chapter has drawn upon the literature to suggest a robust approach to the evaluation of learning spaces. The focus on timing, team and techniques highlights that running an online satisfaction survey once teachers and students have started using the space is not sufficient, and suggests the following take home messages:

- the evaluation strategy should be one of the first considerations when planning a learning spaces project;

- evaluation should be embedded at all stages of the learning spaces project and beyond;

- the evaluation should be aligned with and assess the institutional goals for the learning space project; 
Learning Space Evaluations - Timing, Team, Techniques

- the evaluation should aim to collect information across the complete range of elements of a learning space - from environmental through to pedagogical - to fully understand the successes an issues with the space;

- the evaluation should involve a variety of stakeholders that can bring different perspectives to the development of evaluation instruments, and;

- the evaluation should use a variety of techniques that allows for a complete exploration of how the space impacts learning and teaching.

\section{References}

Anders, D., Calder, A., Elder, K., \& Logan, A. (2008). Investigating the Dynamics of an Integrated Learning Space at James Cook University. In D. Radcliffe, H. Wilson, D. Powell, \& B. Tibbetts (Eds.), Learning spaces in higher education: Positive outcomes by design, St. Lucia: The University of Queensland. $\quad$ Retrieved 2 December 2013 from http://www.uq.edu.au/nextgenerationlearningspace/proceedings

Briden, J. 2007. Photo Surveys: Eliciting More Than You Knew to Ask For. In N. F. Foster \& S. Gibbons (Eds.), Studying Students: The Undergraduate Research Project at the University of Rochester, Association of College and Research Libraries. Retrieved 2 December 2013 from http://www.ala.org/acrl/sites/ala.org.acrl/files/content/publications/booksanddigitalresources/digital/Foster-Gibbons_cmpd.pdf

Brooks, D. C. (2011). Space matters: The impact of formal learning environments on student learning. British Journal of Educational Technology, 42(5), 719-726. doi:10.1111/j.1467-8535.2010.01098.x

Brooks, D. C. (2012). Space and consequences: The impact of different formal learning spaces on instructor and student behavior. Journal of Learning Spaces, 1(2), 1-16.

Clark, K. (2007). Mapping Diaries, or Where Do They Go All Day? In N. F. Foster \& S. Gibbons (Eds.), Studying Students : The Undergraduate Research Project at the University of Rochester. Association of College and Research Libraries. Retrieved 2 December 2013 from http://www.ala.org/acrl/sites/ala.org.acrl/files/content/publications/booksanddigitalresources/digital/Foster-Gibbons_cmpd.pdf

Crisp, G. (2014). Assessment in Next Generation Learning Spaces. In K. Fraser (Ed.), The future of learning and teaching in next generation learning spaces (Vol 12). Bingley, United Kingdom: Emerald Group Publishing.

Dane, J. (2008). Deakin University Immersive Learning Environment (DILE): an evaluation. In D. Radcliffe, H. Wilson, D. Powell, \& B. Tibbetts (Eds.), Learning spaces in higher education: Positive outcomes by design, St. Lucia: The University of Queensland. Retrieved 2 December 2013 from http://www.uq.edu.au/nextgenerationlearningspace/proceedings

Education Queensland (2013). Technology, Architecture and Furniture. Retrieved 2 December 2013 from http://www.learningplace.com.au/deliver/content.asp?pid=49664

Gallagher, A., Pearce, A. \& McCormack, R. (2008). Learning in the Learning Commons: The Learning Commons at City Flinders and St Albans Campuses. In D. Radcliffe, H. Wilson, D. Powell, \& B. Tibbetts (Eds.), Learning spaces in higher education: Positive outcomes by design, St. Lucia: The University of $\begin{array}{lllll}\text { Queensland. } & \text { Retrieved } 2013 & \text { from }\end{array}$ http://www.uq.edu.au/nextgenerationlearningspace/proceedings

Gibbons, S. \& Foster, N. F. (2007). Library Design and Ethnography. In N. F. Foster \& S. Gibbons (Eds.), Studying Students: The Undergraduate Research Project at the University of Rochester. Association of College and Research Libraries. Retrieved 2 December 2013 from http://www.ala.org/acrl/sites/ala.org.acrl/files/content/publications/booksanddigitalresources/digital/Foster-Gibbons_cmpd.pdf 
Learning Space Evaluations - Timing, Team, Techniques Higgins, S., Hall, E., Wall, K., Woolner, P. \& McCaughey, C. (2005), The impact of school environments: A literature review. Retrieved 2 December 2013 from http://www.ncl.ac.uk/cflat/news/DCReport.pdf

Hook, C. M., \& Rosenshine, B. V. (1979). Review of Educational Research, 49(1), 1-12.

Howell, C. (2008). Movers and Shapers: Research Methods Paper. Retrieved 2 December 2013 from http://www.caret.cam.ac.uk/blogs/llp/wp-

content/uploads/lip research20methods moversshapers v03.pdf

Hunley, S. \& Schaller, M. (2006). Assessing Learning Spaces. In D. G. Oblinger (Ed.), Learning Spaces. EDUCAUSE. Retrieved 2 December 2013 from https://net.educause.edu/ir/library/pdf/PUB7102.pdf

Jamieson, P. (2007). Rethinking the University Classroom: Designing 'Places' for Learning. Paper presented at the Inaugural Next Generation Learning Spaces Colloquium.

Jordan, E. \& Ziebell, T. (2008). Learning in the Spaces: A Comparative Study of the Use of Traditional and 'New Generation' Library Learning Spaces by Various Disciplinary Cohorts. In D. Radcliffe, H. Wilson, D. Powell, \& B. Tibbetts (Eds.), Learning spaces in higher education: Positive outcomes by design, St. Lucia: The University of Queensland. Retrieved 2 December 2013 from http://www.uq.edu.au/nextgenerationlearningspace/proceedings

Keppell, M. and Riddle, M. (2012). Distributed Learning Spaces: Physical, Blended and Virtual Learning Spaces in Higher Education. In Keppell, M., Souter, K. and Riddle, M. (Eds.) Physical and Virtual Learning Spaces in Higher Education: Concepts for the Modern Learning Environment. Hershey, PA: IGI Global.

Lee, N. (2008). The Hawthorn Project Hub at Swinburne University of Technology. In D. Radcliffe, H. Wilson, D. Powell, \& B. Tibbetts (Eds.), Learning spaces in higher education: Positive outcomes by design, St. Lucia: The University of Queensland. Retrieved 2 December 2013 from http://www.uq.edu.au/nextgenerationlearningspace/proceedings

Lee, N., \& Tan, S. (2011). Final Report 2011: A comprehensive learning space evaluation model. Retrieved 2 December 2013 from http://www.olt.gov.au/project-comprehensive-learning-spaceswinburne-2008

Lee, N., \& Tan, S. (2013). Traversing the Design-Language Divide in the Design and Evaluation of Physical Learning Environments: A Trial of Visual Methods in Focus Groups. Journal Of Learning Spaces, 2(2).

Lippincott, J. (2007). Assessing Learning Spaces. Paper presented at the Library Assessment Conference, Charlottesville, VA.

Maslow, A. H. (1943). A theory of human motivation. Psychological Review, 50(4).

Psychological Review, 50, 370-396.

Matthews, K. E., Andrews, V., \& Adams, P. (2011). Social learning spaces and student engagement. Higher Education Research \& Development, 30(2), 105-120.

Mitchell, G., Winslett, G., \& Howell, G. (2008). Lab 2.0. In D. Radcliffe, H. Wilson, D. Powell, \& B. Tibbetts (Eds.), Learning spaces in higher education: Positive outcomes by design, St. Lucia: The University of Queensland. Retrieved 2 December 2013 from http://www.uq.edu.au/nextgenerationlearningspace/proceedings

Nixon, A., Tompkins, H., \& Lackie, P. (2008). Curricular Uses of Visual Materials: A Mixed-Method Institutional Study. Northfield, MN: Carleton College, Dean of the College Office. Retrieved 2 December 2013 from http://apps.carleton.edu/curricular/support/assets/CUVMFinal.PDF

Oblinger, D. G. (2004). Leading the Transition from Classrooms to Learning Spaces. Retrieved 2 December from https://net.educause.edu/ir/library/pdf/NLI0447.pdf 
Powell, N. (2008). Evaluation and the Pedagogy-Space-Technology Framework. In D. Radcliffe, $\mathrm{H}$. Wilson, D. Powell, \& B. Tibbetts (Eds.), Learning spaces in higher education: Positive outcomes by design, St. Lucia: The University of Queensland. Retrieved 2 December 2013 from http://www.uq.edu.au/nextgenerationlearningspace/proceedings

Radcliffe, D. (2008). A pedagogy-space-technology (PST) framework for Designing and Evaluating Learning Places. In D. Radcliffe, H. Wilson, D. Powell, \& B. Tibbetts (Eds.), Learning spaces in higher education: Positive outcomes by design, St. Lucia: The University of Queensland. Retrieved 2 December 2013 from http://www.uq.edu.au/nextgenerationlearningspace/proceedings

Radcliffe, D., Wilson, H., Powell, D. \& Tibbetts, B. (2008), Learning spaces in higher education: Positive outcomes by design, St. Lucia: The University of Queensland. Retrieved 2 December 2013 from http://www.uq.edu.au/nextgenerationlearningspace/proceedings

Walker, J. D., Brooks, D. C., \& Baepler, P. (2011). Pedagogy and Space : Empirical Research on New Learning Environments. EDUCAUSE Quarterly, 34(4). Retrieved 2 December from http://www.educause.edu/ero/article/pedagogy-and-space-empirical-research-new-learning-

environments

Whiteside, A. L., Brooks, D. C., \& Walker, J. D. (2010). Making the Case for Space: Three Years of Empirical Research on Learning Environments. EDUCAUSE Review Online. Retrieved 2 December from http://www.educause.edu/ero/article/making-case-space-three-years-empirical-research-learningenvironments

Woolner, P., Clark, J., Hall, E., Tiplady, L., Thomas, U., \& Wall, K. (2010). Pictures are necessary but not sufficient: Using a range of visual methods to engage users about school design. Learning Environments Research, 13(1), 1-22. doi:10.1007/s10984-009-9067-6 